\title{
Use of Cryptates in Bulk Anionic Polymerization of Methyl Methacrylate
}

\author{
S. RAYNAL \\ Centre de Recherches du Bouchet, Société Nationale des \\ Poudres et Explosifs, 91710 Vert-le-Petit, France
}

(Received February 12, 1982)

\begin{abstract}
The purpose of the present work concerning anionic polymerization has been described on the application of the effects of adding cryptands to alkali metals and organometallic derivatives initiating the bulk polymerization of methyl methacrylate. The influences of polymerization temperature and initiator concentration have also been investigated. The presence of complexed ion pairs increases the content of the syndiotactic structure and polymerization seemed to obey Bernouillian statistics.
\end{abstract}

KEY WORDS Poly(methyl methacrylate) / Bulk Polymerization / Microstructure / Cryptand / Molecular Weight /

Many studies on the stereospecific polymerization of methyl methacrylate (MMA) have been carried out. Generally, the organolithium compounds provide isotactic poly(methyl methacrylate) (PMMA) in nonpolar solvents such as toluene in which polymer chain ends are highly associated, and syndiotactic PMMA in polar solvents such as tetrahydrofuran (THF) at low temperature. ${ }^{1-4}$

On the other hand, considerable research has been directed toward increasing the reactivity of anionic initiators by adding aminoalcohols ${ }^{5}$, alkoxyalcohols, ${ }^{5}$ tertiary amines, ${ }^{6}$ alkali alkoxides, ${ }^{7-14}$ macrocyclic polyethers, ${ }^{15}$ cryptands, ${ }^{16}$ and by the formations of heterogeneous complexes. ${ }^{17-19}$ Macroheterobicyclic ligands such as cryptands lead to the formation of polar structures thus indicating the presence of extremely reactive complexed ion pairs. ${ }^{16}$

In the present work concerning anionic polymerization an attempt has been made to show the application of cryptands toward preparing new complexed initiators without solvents. We studied the influence of these species on the yield and stereoregularity in bulk polymerization of MMA.

\section{EXPERIMENTAL}

Ligand (Cryptands). The (222) compound (diaza-1,10-hexaoxa-4,7,13,16,21,24-bicyclo-8,8,8hexacosane) was purified by freeze drying in benzene and sealed under high vacuum in glass tubes fitted with breakable seals. The same procedure was applied to freshly distilled (221) and (211) compounds (diaza-1,10-pentaoxa-4,7,13,16,21-bicyclo5,8,8-triacosane and diaza-1,10-tetraoxa-4,7,13,18) bicyclo-5,5,8-eicosane).

Solutions of BuLi, MeLi, and PhLi commercially available were introduced into a reactor under stirring with a hypodermic syringe under argon, then the solvent was evaporated under vaccum.

Alkali Carbazyl. The carbanion salts were prepared under vacuum in THF from carbazole and an alkali mirror obtained under high vacuum by subliming high purity metals. After titration by a UV spectrophotometer, the solvent was evaporated under vacuum.

Methyl Methacrylate (MMA). MMA was distilled under argon at reduced pressure. The middle fraction was introduced into a glass apparatus under high vacuum and then stored in the dark at $-30^{\circ} \mathrm{C}$, in tubes fitted with breakable seals.

Polymerization Procedure. Polymerization was carried out in a glass apparatus sealed under high vacuum. Following the addition of ligands to the initiator, the monomer was introduced into the same reactor. The reaction mixtures were stirred at 
the desired temperature. After a certain period of time, polymerization was made to stop by adding a small amount of $\mathrm{MeOH}$. The polymer was precipitated by pouring the reaction mixture into a large excess of methanol.

\section{NMR Measurements}

${ }^{1} \mathrm{H}$ NMR spectra were measured for $10-20 \%$ polymer solutions in ortho-dichlorobenzene at $150^{\circ} \mathrm{C}$ with a Varian spectrometer (Model HA $100)$.

\section{RESULTS AND DISCUSSION}

\section{Effects of Cryptand Addition on the MMA/RLi} Polymerization System without Solvent

The yield and the stereoregularity of polymers obtained with butyllithium as the initiator in the presence of various amounts of (211) are shown in Table I. It can be seen that the syndiotacticity increased even when the amount of cryptand added was small. However, when the molar ratio of (211)/ BuLi was higher than 0.2 the stereoregularity remained unchanged (Figure 1). From Table $I$ it is apparent that the polymers are mostly syndiotactic and their proportion to each other was roughly independent of temperature and the nature of the initiator and ligand. High conversion was obtained in all cases of polymerization. The cation was complexed by the macroheterobicycle and the conformation of the carbanion end group of the growing polymer chain was assumed to be such as would incur the greatest probability of attack. This conformation permitted the least degree of steric strain, thus leading to syndiotactic placement. Similar conclusions were reached in regard to solution polymerization with the same ligands. ${ }^{15,16}$

It was noticed that an induction period of initiation was required for the slow starting of polymerization. During this period, the initiator dissolved into the monomer. The polarity of the monomer facilitated the dissolution of the initiator. The rate of propagation was too high to permit measurement. The considerable differences between the experimental and calculated molecular weights may be explained by the fact that as soon as active centers were formed and complexed by the macroheterobicycle, the reactivity of new species considerably increased in such a way that only a part of the original initiator actually

Table I. Effects of cryptands on the polymerization system MMA/RLi

\begin{tabular}{|c|c|c|c|c|c|c|c|c|c|c|}
\hline \multirow{2}{*}{ Initiator $^{\mathbf{a}}$} & \multirow{2}{*}{$r^{\mathrm{b}}$} & \multirow{2}{*}{$\frac{\text { Temp }}{{ }^{\circ} \mathrm{C}}$} & \multirow{2}{*}{$\frac{\text { Yield }}{\%}$} & \multirow{2}{*}{$M_{n}^{\mathrm{c}}$} & \multirow{2}{*}{$M_{w}{ }^{\mathrm{c}}$} & \multirow{2}{*}{$M_{w} / M_{n}^{\mathrm{c}}$} & \multicolumn{3}{|c|}{ Microstructure } & \multirow{2}{*}{$\rho$} \\
\hline & & & & & & & $\mathrm{i}$ & $\mathrm{h}$ & $\mathrm{s}$ & \\
\hline $\mathrm{BuLi}$ & - & 20 & 60 & 147,000 & 392,000 & 2.7 & 58 & 32 & 10 & 1.20 \\
\hline BuLi-211 & 1 & 20 & 87 & 206,000 & 602,000 & 2.9 & 8 & 40 & 52 & 1.01 \\
\hline BuLi-211 & 0.8 & 20 & 88 & 208,000 & 504,000 & 2.4 & 8 & 39 & 53 & 1.03 \\
\hline BuLi-211 & 0.5 & 20 & 80 & 175,400 & 458,000 & 2.6 & 9 & 40 & 51 & 1.03 \\
\hline BuLi-211 & 0.3 & 20 & 75 & 197,300 & 617,000 & 3.1 & 10 & 37 & 53 & 1.10 \\
\hline BuLi-211 & 0.2 & 20 & 75 & 152,800 & 327,000 & 2.1 & 15 & 40 & 45 & 1.14 \\
\hline BuLi-211 & 0.1 & 20 & 70 & 141,400 & 297,000 & 2.1 & 20 & 40 & 40 & 1.20 \\
\hline BuLi-211 & 0.05 & 20 & 65 & 103,000 & 206,500 & 2.0 & 54 & 32 & 14 & 1.31 \\
\hline BuLi-221 & 1 & 20 & 85 & 187,800 & 437,000 & 2.3 & 9 & 40 & 51 & 1.03 \\
\hline BuLi-222 & 1 & 20 & 80 & 159,600 & 397,600 & 2.5 & 8 & 39 & 53 & 1.03 \\
\hline MeLi-211 & 1 & 20 & 90 & 137,900 & 283,900 & 2.1 & 8 & 38 & 54 & 1.04 \\
\hline PhLi-211 & 1 & 20 & 100 & 210,000 & 417,800 & 2.0 & 9 & 40 & 51 & 1.03 \\
\hline BuLi-211 & 1 & 0 & 95 & 195,000 & 703,500 & 3.6 & 7 & 39 & 54 & 1.00 \\
\hline BuLi-211 & 1 & -20 & 100 & 199,900 & 504,200 & 2.5 & 8 & 40 & 52 & 1.01 \\
\hline BuLi-211 & 1 & -50 & 95 & 217,500 & 607,300 & 2.8 & 7 & 39 & 54 & 1.00 \\
\hline BuLi-211 & 1 & -78 & 95 & 187,400 & 459,800 & 2.5 & 9 & 40 & 51 & 1.03 \\
\hline
\end{tabular}

Polymerization time, $20 \mathrm{~min}$.

a RLi, 2 mmol; MMA, $100 \mathrm{mmol}$.

b $r$, cryptand/RLi molar ratio.

c Measured by GPC at $30^{\circ} \mathrm{C}$ in THF. 


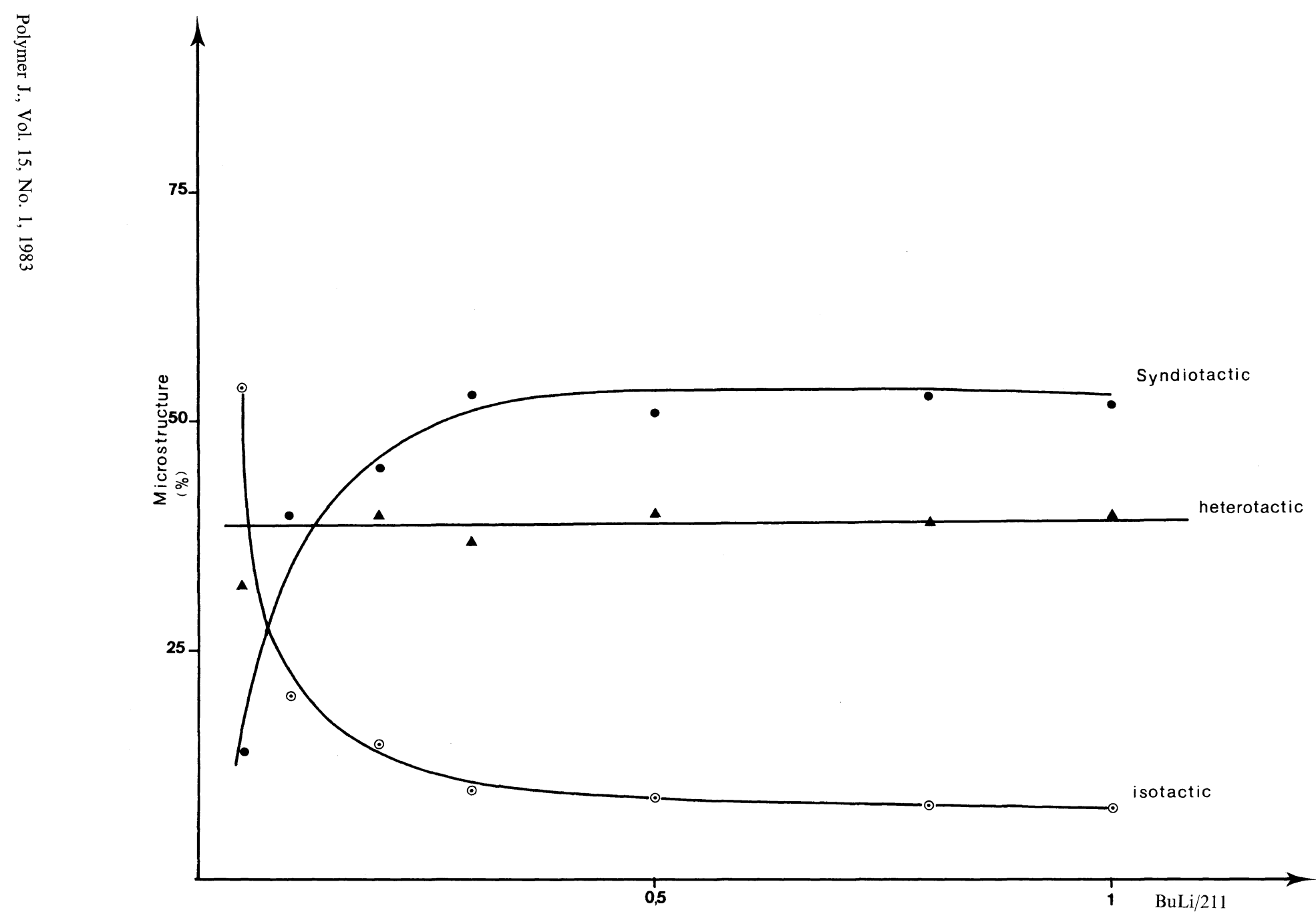

Figure 1. Effects of cyrptands/BuLi molar ratio on polymer tacticity. 
S. RAYNAL

Table II. Effects of cryptands on the MMA/alkali carbazyl polymerization system

\begin{tabular}{|c|c|c|c|c|c|c|c|c|c|}
\hline \multirow{2}{*}{ Initiator $^{\mathrm{a}}$} & \multirow{2}{*}{$\frac{\text { Temp }}{{ }^{\circ} \mathrm{C}}$} & \multirow{2}{*}{$\frac{\text { Yield }}{\%}$} & \multirow{2}{*}{$M_{n}^{\mathrm{b}}$} & \multirow{2}{*}{$M_{w}{ }^{\mathrm{b}}$} & \multirow{2}{*}{$M_{w} / M_{n}^{\mathrm{b}}$} & \multicolumn{3}{|c|}{ Microstructure } & \multirow{2}{*}{$\rho$} \\
\hline & & & & & & $\mathrm{i}$ & $\mathrm{h}$ & $\mathrm{s}$ & \\
\hline \multirow{5}{*}{$\begin{array}{l}\text { Carbazyl } \mathrm{Na} \\
\quad-221\end{array}$} & 20 & 80 & 217,000 & 403,000 & 1.9 & 8 & 39 & 53 & 1.03 \\
\hline & 0 & 82 & 204,000 & 417,000 & 2.0 & 7 & 40 & 53 & 1.04 \\
\hline & -20 & 85 & 233,000 & 522,000 & 2.2 & 8 & 41 & 51 & 0.99 \\
\hline & -50 & 80 & 197,500 & 485,800 & 2.5 & 6 & 39 & 55 & 0.97 \\
\hline & -78 & 83 & 208,300 & 497,300 & 2.4 & 8 & 40 & 52 & 1.01 \\
\hline \multirow{5}{*}{$\begin{array}{l}\text { Carbazyl K } \\
-222\end{array}$} & 20 & 92 & 302,000 & 597,800 & 2.0 & 7 & 38 & 55 & 1.01 \\
\hline & 0 & 90 & 287,500 & 603,400 & 2.1 & 7 & 40 & 53 & 1.04 \\
\hline & -20 & 95 & 293,400 & 627,900 & 2.1 & 8 & 39 & 53 & 1.03 \\
\hline & -50 & 90 & 199,800 & 604,500 & 3.0 & 8 & 40 & 52 & 1.01 \\
\hline & -78 & 94 & 213,500 & 503,700 & 2.4 & 7 & 40 & 53 & 0.99 \\
\hline
\end{tabular}

Polymerization time, $20 \mathrm{~min}$; MMA, $100 \mathrm{mmol}$.

a Alkali carbazyl/cryptand, $1 \mathrm{mmol} / 1 \mathrm{mmol}$.

b Measured by $\mathrm{GPC}$ at $30^{\circ} \mathrm{C}$ in $\mathrm{THF}$.

participated.

Effects of Cryptand Addition on the MMA/Alkali Carbazyl Polymerization System without Solvent

As it was shown in the experimental section alkali carbazyls were prepared in a solvent from which the solvents were subsequently evaporated. The most important results of the polymerization are presented in Table II. The presence of macroheterobicycles led to the formation of complexed ion pairs, considerably enhancing the reactivity of the active species. The complexation of cation by the macroheterobicycle annihilates all other solvations and the microstructure of polymer remains unchanged owing to the nature of cation and of the temperature. Similar results were obtained for solution, ${ }^{26}$ but since no solvent was used in the present studies, the formation of very reactive complexed ion pairs during the polymerization led to an increase in polymerization rate and the formation of a polar structure.

On all occasions, it was observed that, as in the case of organolithiums, an induction period was required for initiation (Figure 2). This period varied according to the counterion and was less than that for organolithium compounds. Thus, it may be considered that the rates of the complexation and the solubilization of the initiator are promoted by the residual solvent present in the preparations of initiator which decreases the period of induction and increases the rate of initiation.

Effects of Addition of Cryptands on the Polymerization System MMA/Metal without Solvent

Macroheterobicycles form with alkali metals stable complexes which serve as good initiators in the anionic polymerization of vinyl monomers. ${ }^{16,20-23}$ In Table III, the results of bulk polymerization of MMA initiated by various alkali metals are summarized.

As expected, the microstructure of the polymers obtained does not depend on counterions and temperature and is very different from that obtained without ligands. However, if a complex leading to a very reactive species is formed, the actual structure of the complex naturally becomes more complicated than that in the case of a solution.

The effect of the macroheterobicycle cannot be represented by equilibrium between tight ion pairs, loose ion pairs, and free ions as in the case of alkali metals in solution. However the polarity of the monomer studied here makes it permissable to consider that the small fraction of metal is soluble in the monomer which functions as a solvent.

The initiation induction period mentioned above is more important at this point in consideration of the greater difficulty in dissolving a metal mirror than organometallic compounds (Figure 2). 


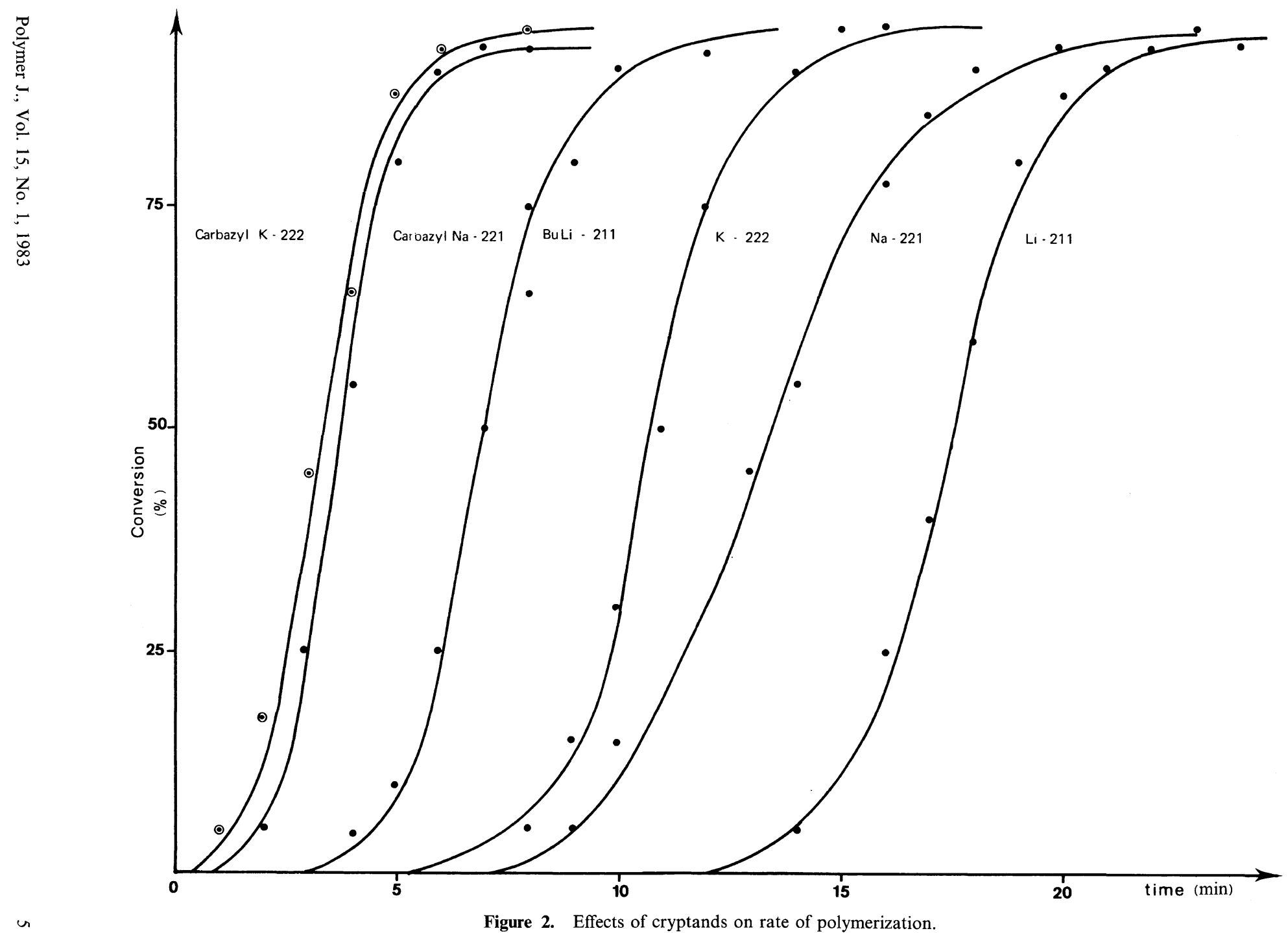

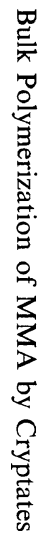

Figure 2. Effects of cryptands on rate of polymerization 


\section{S. RAYNAL}

Table III. Effects of cryptands on the MMA/metal polymerization system

\begin{tabular}{|c|c|c|c|c|c|c|c|c|c|}
\hline \multirow{2}{*}{ Initiator $^{\mathrm{a}}$} & \multirow{2}{*}{$\frac{\text { Temp }}{{ }^{\circ} \mathrm{C}}$} & \multirow{2}{*}{$\frac{\text { Yield }}{\%}$} & \multirow{2}{*}{$M_{n}^{\mathrm{b}}$} & \multirow{2}{*}{$M_{w}^{\mathrm{b}}$} & \multirow{2}{*}{$M_{w} / M_{n}^{\mathrm{b}}$} & \multicolumn{3}{|c|}{ Microstructure } & \multirow{2}{*}{$\rho$} \\
\hline & & & & & & $\mathrm{i}$ & $\mathrm{h}$ & $\mathrm{s}$ & \\
\hline $\mathrm{Li}$ & 20 & 47 & 102,000 & 214,000 & 2.1 & 58 & 32 & 10 & 1.20 \\
\hline $\mathrm{Na}$ & 20 & 60 & 107,000 & 231,000 & 2.2 & 23 & 53 & 24 & 0.94 \\
\hline $\mathrm{K}$ & 20 & 68 & 115,000 & 218,000 & 1.9 & 20 & 50 & 21 & 0.93 \\
\hline $\mathrm{Li}-211$ & 20 & 85 & 152,000 & 317,000 & 2.1 & 8 & 39 & 53 & 1.01 \\
\hline $\mathrm{Na}-221$ & 20 & 85 & 240,000 & 425,000 & 1.8 & 7 & 38 & 55 & 1.01 \\
\hline $\mathrm{K}-222$ & 20 & 90 & 286,000 & 632,000 & 2.2 & 6 & 39 & 55 & 0.97 \\
\hline $\mathrm{Rb}-222$ & 20 & 80 & 197,500 & 447,000 & 2.3 & 6 & 37 & 53 & 0.99 \\
\hline Cs -222 & 20 & 85 & 199,300 & 715,000 & 3.6 & 6 & 40 & 54 & 0.96 \\
\hline $\mathrm{Li}-211$ & -78 & 75 & 230,000 & 368,000 & 1.6 & 7 & 39 & 54 & 1.00 \\
\hline $\mathrm{Na}-221$ & -78 & 85 & 198,400 & 317,500 & 1.6 & 6 & 39 & 55 & 0.97 \\
\hline $\mathrm{K}-222$ & -78 & 100 & 212,800 & 617,000 & 2.9 & 5 & 39 & 56 & 0.95 \\
\hline $\mathrm{Rb}-222$ & -78 & 95 & 181,250 & 580,000 & 3.2 & 7 & 39 & 54 & 1.00 \\
\hline Cs-222 & -78 & 100 & 117,500 & 975,600 & 8.3 & 7 & 40 & 53 & 0.99 \\
\hline $\mathrm{Na}-221$ & 0 & 95 & 212,100 & 403,000 & 1.9 & 6 & 39 & 55 & 0.97 \\
\hline $\mathrm{Na}-221$ & -20 & 90 & 160,800 & 402,000 & 2.5 & 6 & 39 & 55 & 0.97 \\
\hline $\mathrm{Na}-221$ & -50 & 90 & 218,700 & 503,000 & 2.3 & 7 & 38 & 55 & 1.01 \\
\hline
\end{tabular}

Polymerization time, $20 \mathrm{~min}$; MMA, $100 \mathrm{mmol}$.

a Cryptand, $1 \mathrm{mmol}$.

b Measured by GPC at $30^{\circ} \mathrm{C}$ in THF.

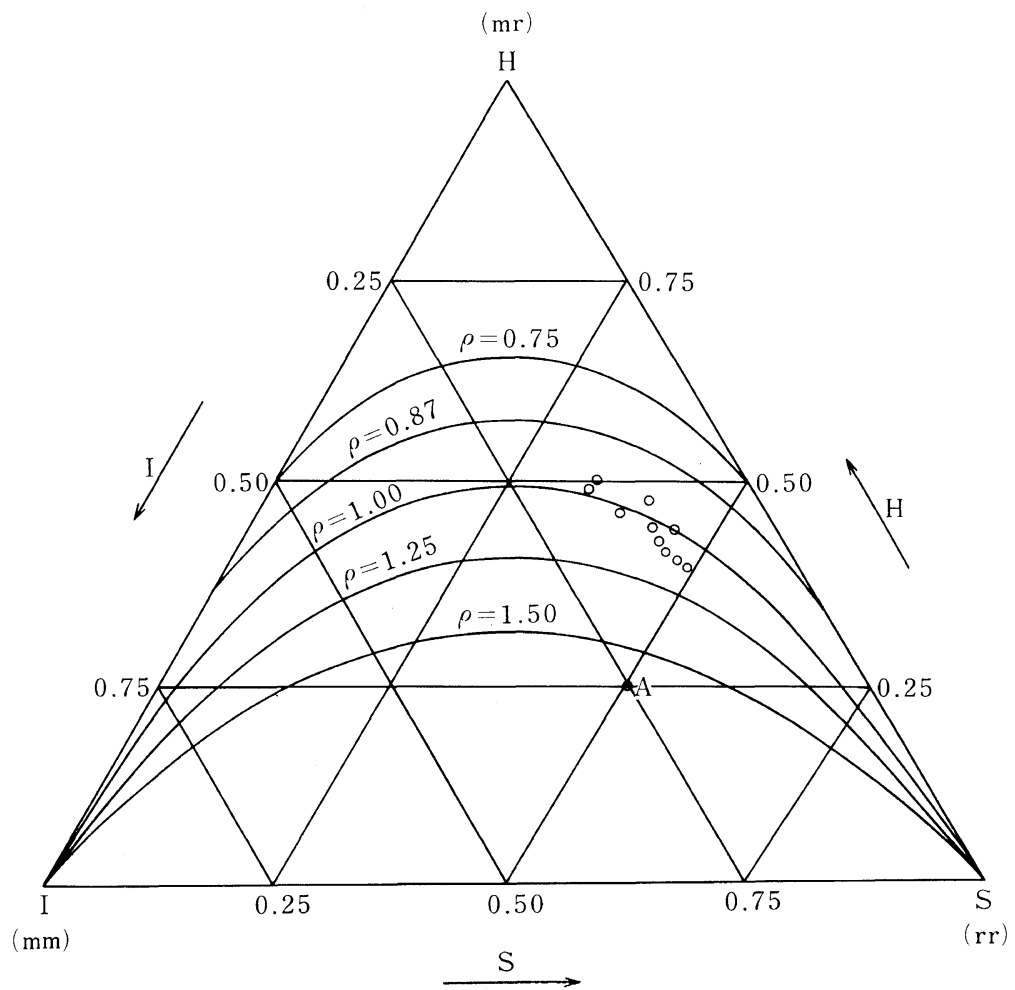

Figure 3. Geometrical presentation of observed triads. 


\section{Chain Statistics}

From Tables I, II, and III, it can be seen that the values of $\rho$ (persistance ratio) defined by Colemand and Fox ${ }^{24,25}$ are near unity (Figure 3). Therefore the polymerization mechanism of MMA initiated by the cryptates in bulk polymerization obeys Bernouillian statistics and confirms the absence of penultimate effects.

\section{CONCLUSIONS}

We obtained complexed ion pairs (called cryptates) in bulk polymerization in which all interactions between cations and reactions mixture, were done away with.

The polymers obtained were mostly syndiotactic and the fraction of racemic dyads was roughly independent of the nature of cations whose nature had become obscure through complexation. In all cases, polymerization was found to apparently obey Bernouillian statistics.

\section{Acknowledgement}

We thank Pr. Schue (Université de Montpellier) and Dr. Boileau (Université de Paris VI) for fruitful discussions and for valuable collaboration.

\section{REFERENCES}

1. D. Braun, M. Herner, U. Johnsen, and W. Kern, Makromol. Chem., 15, 51 (1962).

2. D. L. Glusker, R. A. Galluccio, and R. A. Evans, J. Am. Chem. Soc., 86, 187 (1964).

3. T. Tsuruta, T. Makimoto, and Y. Nakayama, Makromol. Chem., 12, 90 (1966).

4. G. L'Abbe and G. Smets, J. Polym. Sci., A-1, 5, 1359 (1967).

5. M. Maruhashi and H. Takida, Makromol. Chem., 172, 124 (1969).

6. K. Matsuzaki, Y. Nishida, H. Kumahara, T.
Miyabayashi, and T. Yasukawa, Makromol. Chem., 139, 167 (1973).

7. L. Lochmann and D. Lim, J. Organometal. Chem., 50, 9 (1973).

8. L. Lochmann and J. Trekoval, J. Organometal. Chem., 99, 329 (1975).

9. L. Lochmann, M. Rodova, J. Petranek, and D. Lim, J. Polym. Sci., Polym. Chem. Ed., 12, 2295 (1974).

10. D. Wiles and S. Bywater, J. Phys. Chem., 68, 1983 (1964).

11. D. Wiles and S. Bywater, Trans. Faraday Soc., 61, 150 (1965).

12. L. Lochmann, M. Rodova, and J. Trekoval, J. Polym. Sci., Polym. Chem. Ed., 12, 2091 (1974).

13. H. L. Hsieh and C. F. Wofford, J. Polym. Sci., A-1, 7, 449 (1969).

14. L. Lochmann, D. Doskocilova, and J. Trekoval, Collect. Czech. Chem. Commun., 42, 1335 (1977).

15. S. Alev, A. Collet, M. Viguier, and F. Schué, J. Polym. Sci., Polym. Chem. Ed., 18, 1155 (1980).

16. M. Viguier, M. Abadie, F. Schué, and B. Kaempf, Eur. Polym. J., 13, 213 (1977).

17. S. Raynal, S. Lecolier, G. Ndebcka, and P. Caubère, J. Polym. Sci., Polym. Lett. Ed., 13, 18 (1980).

18. G. Ndebeka, P. Caubère, S. Raynal, and S. Lecolier, Polymer, 22, 347 (1981).

19. S. Raynal, S. Lecolier, G. Ndebeka, and P. Caubère, Polymer, 22, 356 (1981).

20. S. Boileau, B. Kaempf, J. M. Lehn, and F. Schué, $J$. Polym. Sci., Polym. Lett. Ed., 12, 203 (1974).

21. S. Boileau, B. Kaempf, S. Raynal, J. Lacoste, and F. Schué, J. Polym. Sci., Polym. Lett. Ed., 12, 211 (1974).

22. S. Boileau, P. Hemery, B. Kaempf, F. Schué, and M. Viguier, J. Polym. Sci., Polym. Lett. Ed., 12, 217 (1974).

23. J. M. Lehn, S. Boileau, B. Kaempf, F. Schué, A. Cau, J. Moinard, and S. Raynal. Br. Fr. n 2398079.

24. B. D. Coleman and T. G Fox, J. Polym. Sci., A, 1, 3183 (1963).

25. B. D. Coleman and T. G Fox, J. Chem. Phys., 38, 1065 (1963).

26. D. Lassalle, Thesis, Paris, 1972. 